\title{
Implicações do conhecimento corporal no comportamento sexual
}

CDD. 20.ed. 301.418

616.89
Fernando Luiz CARDOSO*

Ana Carolina SAVALL*

Samantha SABBAG*

Aline Knepper MENDES*

Thais Silva BELTRAME*
*Centro de Educação

Física e Desportos,

Universidade do Esta-

do de Santa Catarina.

\section{Resumo}

A pesquisa almejou identificar e comparar aspectos da corporeidade e sexualidade de homens ( $n=54)$ e mulheres $(n=54)$ com distintas orientações sexuais e de gênero, participantes do "I Jogos da Diversidade" realizado em Florianópolis, em julho de 2006, mediante aplicação anônima do Questionário de Identidade Corporal - OIC. Os principais objetivos deste estudo foram identificar as diferenças em termos de corporeidade e sexualidade entre homens e mulheres, o perfil sexual de homens e mulheres, bem como o perfil da satisfação corporal e sexual para cada sexo. Os participantes que afirmam gostar do corpo tendem a considerá-lo fisicamente bonito e proporcional, como também causar boa impressão. Participantes que relatam sentir satisfação corporal tendem a encontrar-se sexualmente satisfeitos, porém ao se controlar o sexo biológico, a correlação é verificada apenas entre os homens, os quais também demonstram tendência a ter maior intimidade corporal enquanto as mulheres valorizam carícias íntimas preliminares. Participantes com parceiro fixo chegam mais rápido ao orgasmo, embora reações corporais sejam percebidas mais comumente entre as mulheres.

Unitermos: Sexualidade; Corporeidade; Homem; Mulher; Diversidade.

\section{Introdução}

Apesar da diversidade biológica e fenotípica do "homo sapiens", pode-se dizer que há um aparato corporal universal. Entretanto, a percepção dessa estrutura morfofuncional é variada e muito relativa. De acordo com os valores culturais de cada sociedade, o corpo e suas particularidades ocupam diferentes espaços e "status" na organização social, material e simbólica (DAVIS, 1979). O ser humano, enquanto animal simbólico, toma consciência do seu corpo ou de si mesmo ao longo do desenvolvimento ontogenético. É importante salientar que este processo de reconhecer-se em uma sociedade industrializada estrutura-se a partir de uma categoria social, o "indivíduo", que geralmente é percebido pelo senso comum como uma categoria "natural" e universal (DUMONT, 1970).

A ênfase na noção de "indivíduo" em nossa sociedade "civilizada" favoreceu a percepção de uma natureza biológica pronta e autônoma (CARDOSO, 1994a). Assim, não temos rituais de construção física do corpo como em muitas sociedades indígenas ameríndias que se estruturam na concepção de "pessoa", pois, a priori, em nossa sociedade se nasce pronto (Viveiros de Castro, 1987).

A primeira abordagem antropológica a respeito do uso do corpo foi realizada por MAuss (1974) que sistematizou as maneiras como os homens, sociedade por sociedade, tradicionalmente sabem servir-se de seus corpos - formas estas denominadas por ele de "técnicas corporais". No entanto, em culturas que enfatizam o consumo como sentido existencial existe o controle do corpo com o objetivo de colocá-lo em acordo com os valores de funcionalidade e estética vigentes em distintas épocas de nossa civilização. RoDRIGUEs (1996) considera o aprendizado de uma técnica corporal como parte da construção da percepção de um corpo e afirma que, a partir de um substrato morfofuncional, se constrói a prática cultural. Já Douglas (1970) considera a existência de "dois corpos", um físico e outro social, que encontram-se em profunda interação, sendo o primeiro objeto das ciências biológicas e o segundo, das ciências sociais. 
Além do impacto da cultura na percepção corporal durante o desenvolvimento humano, também salientam-se as influências biológicas do dimorfismo sexual de nossa espécie, o qual se estrutura em machos (com pênis, testículos) e fêmeas (vulva, útero e ovários) (BRANnON, 1999). Por muito tempo, esses marcadores anatômicos serviram para dar suporte ao conhecido conceito antropológico de "papéis sexuais", isto é, as funções sociais acessíveis ou restritivas a homens e mulheres. A criação do conceito de papéis de gênero foi de grande valia, mas de certa forma voltou a naturalizar os atributos do masculino e feminino ao estabelecer a expectativa de "padróes sexuais" sempre atrelados ao sexo biológico.

No meio acadêmico, o termo gênero começou a ser utilizado na década de 70 como um conceito que indica a rejeição ao determinismo biológico implícito no uso de termos como sexo ou diferenciação sexual. $\mathrm{O}$ mundo acadêmico a partir desse momento adquiriu uma nova noção relacional de análise (SCOTT, 1990). Para CARdoso (1994b), o gênero constitui-se na identidade do corpo, referindo-se às origens eminentemente sociais sendo, por exemplo, a fisiologia e a biomecânica humanas aspectos biológicos enquanto o atleta e o resultado esportivo, construções humanas e sociais, assim como a ciência.

As categorias sociais "indivíduo" (detentora de direitos e deveres universais) e "pessoa" (estruturada por relações múltiplas e particulares), além de estruturarem-se a partir de um corpo biologicamente dimórfico e das construções sociais dos papéis de gênero, também são funcional e simbolicamente sensuais e sexuais (CARDOSO, 1997). Esta fusão entre natureza e cultura é o que caracteriza a natureza humana e nos faz seres afetivo-sexuais, e não somente, seres com comportamento sexual reprodutivo.

A sexualidade humana designa o complexo de impulsos, atitudes, hábitos e ações de um ser em busca do orgasmo, que pode ter origem física ou psicogênica, isto é, motivamo-nos sexualmente pelo toque, imagens e/ou pensamentos. FoucaulT (1988) enfatiza que a família tornou-se um dos espaços estruturados das formas de sexualidade, principalmente por meio do matrimônio, que instaurou a economia do prazer.

Homens e mulheres, além das diferenças dimórficas, apresentam distintas experiências no processo de assimilação dos papéis de gênero indicados para cada sexo, o que caracteriza também diferentes percepçôes sobre a sua sexualidade (BRANNON, 1999). O autoconhecimento corporal resulta em implicações na saúde física e psíquica quando pode prevenir e reconhecer a presença de patologias, bem como estruturar e melhorar a auto-estima.

Esse artigo almeja produzir e organizar dados empíricos sobre a corporeidade de homens e mulheres e sua relação com a sexualidade humana. Assim, objetiva identificar quais são as diferenças em termos de corporeidade e sexualidade entre homens e mulheres; o perfil sexual de homens e mulheres; bem como o perfil da satisfação corporal e sexual de cada sexo. Nesse sentido, esta pesquisa pretende entender o impacto da corporeidade de homens e mulheres sobre o comportamento sexual, a partir da autoavaliação dos participantes de um evento esportivo, que conglomerou grande diversidade de gênero e sexual em Florianópolis/SC.

\section{Metodologia}

Trata-se de uma pesquisa não-probabilística descritiva correlacional, que teve como principal objetivo comparar aspectos da corporeidade e sexualidade de homens e mulheres em uma oportunidade esportiva única, o "I Floripa Diversity Games", realizado em julho de 2006 nas instalaçóes do Centro de Ciências da Saúde e do Esporte - CEFID da Universidade do Estado de Santa Catarina - UDESC, em Florianópolis, a qual congregou grande diversidade de gênero e sexual. Esta coleta faz parte de uma ampla pesquisa aprovada pelo Comitê de Ética em Pesquisa em Seres Humanos (CEPSH) da UDESC, sob o número de referência $40 / 05$. Os primeiros jogos da diversidade aconteceram no dia anterior à primeira Parada Gay e teve como objetivo promover a integração da diversidade sexual humana por meio de atividades esportivas recreativas, não destinadas especificamente a atletas ou competição.

\section{Participantes}

Participaram desta pesquisa não apenas esportistas GLBTS (gays, lésbicas, bissexuais, transexuais e simpatizantes), mas também comissão organizadora, voluntários e acadêmicos de Educação Física responsáveis pela arbitragem. Como esperado pela equipe organizadora, participaram deste 
primeiro evento poucos participantes gays, lésbicas, bissexuais e transexuais, provavelmente pelo receio de exposição social, devido a visibilidade que a mídia dá a esses eventos. Considerando o número de envolvidos no evento, quase todos os presentes ( $\mathrm{n}$ $=108$ ) aceitaram participar espontaneamente desta pesquisa. Os detalhes sobre o perfil dos sujeitos podem ser vistos na TABELA 1.

Dentre os participantes, 38 (70,4\%) homens e 24 $(44,4 \%)$ mulheres declararam realizar alguma atividade física regularmente. Na TABELA 2 encontram-se as atividades físicas praticadas pelos participantes.

TABELA 1 - Perfil social e de orientação sexual dos homens e mulheres participantes.

\begin{tabular}{lccc}
\hline \multicolumn{1}{c}{ Parâmetros } & Homossexuais & Bissexuais & Heterossexuais \\
\hline $\mathrm{N}$ & $18(34,6 \%)$ & $6(11,1 \%)$ & \\
Idade $^{1}$ & $30,5( \pm 9,2)$ & $31,2( \pm 7,0)$ & $28(53,8 \%)$ \\
Itens de consumo $^{2}$ & $2,3( \pm 1,1)$ & $2,8( \pm 1,0)$ & $2,1( \pm 1,2)$ \\
Nível universitário $^{3}$ & $10(55,6 \%)$ & $3(50 \%)$ & $19(63,3 \%)$ \\
Solteiros $^{4}$ & $18(100 \%)$ & $5(83,3 \%)$ & $16(53,3 \%)$ \\
Praticam atividade física $^{5}$ & $13(72,2 \%)$ & $4(66,7 \%)$ & $21(70 \%)$ \\
\hline & $18(33,4 \%)$ & $6(11,1 \%)$ & $30(55,6 \%)$ \\
\hline N & $27,8( \pm 7,7)$ & $22,2( \pm 3,0)$ & $29,9( \pm 10,7)$ \\
Idade $^{1}$ & $2,0( \pm 1,2)$ & $3,0( \pm 1,1)$ & $2,1( \pm 1,0)$ \\
Itens de consumo $^{2}$ & $5(27,8 \%)$ & $3(50 \%)$ & $22(73,3 \%)$ \\
Nível universitário $^{3}$ & $10(55,6 \%)$ & $3(50 \%)$ & $16(53,3 \%)$ \\
Solteiros $^{4}$ & $8(44,4 \%)$ & $4(66,7 \%)$ & $12(40 \%)$ \\
Praticam atividade física $^{5}$ & & & \\
\hline
\end{tabular}

TABELA 2 - Práticas esportivas realizadas regularmente pelos homens e mulheres participantes, de acordo com a orientação sexual.

\begin{tabular}{|c|c|c|c|}
\hline Atividades esportivas* & Homossexuais & Bissexuais & Heterossexuais \\
\hline \multicolumn{4}{|c|}{ Homens $(\mathrm{N}=54)$} \\
\hline $\mathrm{N}$ & $18(34,6 \%)$ & $6(11,1 \%)$ & $28(53,8 \%)$ \\
\hline Futebol & 1 & - & 4 \\
\hline Voleibol & 4 & 1 & - \\
\hline Natação & 1 & 1 & 1 \\
\hline Caminhada & 3 & - & 5 \\
\hline Dança & 2 & - & - \\
\hline Musculação & 2 & 1 & 1 \\
\hline Artes marciais & - & 1 & 5 \\
\hline Ciclismo & - & - & 1 \\
\hline Surf & - & - & 1 \\
\hline Total de respondentes & 13 & 4 & 18 \\
\hline \multicolumn{4}{|c|}{ Mulheres $(\mathrm{N}=54)$} \\
\hline $\mathrm{N}$ & $18(33,4 \%)$ & $6(11,1 \%)$ & $30(55,6 \%)$ \\
\hline Futebol & 3 & - & 1 \\
\hline Caminhada & 2 & - & 4 \\
\hline Dança & - & 2 & - \\
\hline Musculação & - & - & 2 \\
\hline Ciclismo & 1 & - & - \\
\hline Ginástica & - & 1 & 4 \\
\hline Total de respondentes & 6 & 3 & 11 \\
\hline
\end{tabular}

Observações:

1. Questão: Idade (em anos):__anos. Média aritmética da idade dos sujeitos.

2. Questão: Quais desses itens você tem em casa? ( ) Ar Condicionado, ( ) TV a cabo, ( ) Carro, ( ) Computador

3. Questão: Qual o seu grau de escolaridade? ( ) primeiro grau incompleto, ( ) primeiro grau completo, ( ) segundo grau incompleto, ( ) segundo grau completo, ( ) universidade incompleta ( ), universidade completa. Percentagem dos participantes com nível universitário.

4. Questão: Qual é o seu estado civil? ( ) solteiro, ( ) casado, ( ) separado, ( ) viúvo, ( ) união estável. Percentagem dos participantes solteiros.

5. Questão: Você pratica atividade física regularmente (mínimo de $2 \mathrm{X}$ semana): ( ) sim, ( ) não
Observação: * Questão aberta: Qual atividade física você pratica regularmente? 


\section{Instrumento}

Esta pesquisa utilizou-se do método de autorelato mediante aplicação do Questionário de Identidade Corporal (QIC), instrumento autoresponsivo desenvolvido pelo Laboratório de Gênero, Sexualidade e Corporeidade do CEFID - UDESC, o qual é constituído por três dimensões: sexualidade, corporeidade e motricidade, avaliadas em 10 escalas: intimidade corporal, percepção corporal, satisfação corporal, pré-disposição sexual, comportamento sexual, orientação sexual, satisfação sexual, experiências motoras, orientação motora e identidade infantil. Cada escala é medida por meio de Escala Likert de sete níveis (nunca - médio - muito, quantificados de $0 \mathrm{a} 6$ ). O questionário também possui questôes sociodemográficas (idade, profissão, estado civil, sexo biológico, gênero, orientação sexual, itens de consumo residenciais, grau de escolaridade e prática de atividade física regular).

\section{Resultados}

Diferenças em termos de corporeidade e sexualidade entre homens e mulheres

Com referência ao aspecto "relação com o corpo", há diferença significativa entre os participantes do sexo masculino e feminino nos quesitos "visualização da genitália", "conhecimento da própria genitália" e "toque da sua genitália", onde os homens demonstraram maior intimidade com o seu corpo. Entretanto, nesse mesmo aspecto, as mulheres tendem a se olhar mais no espelho que os homens.

No aspecto "comportamento sexual", os homens fazem sexo no primeiro encontro mais frequentemente que as mulheres. No aspecto orientação

\section{Coleta de dados}

Participaram da coleta dos dados três mestrandos e quatro bolsistas de iniciação à pesquisa, os quais abordavam os sujeitos explicando os objetivos do estudo e solicitavam a participação anônima. Após o preenchimento, os questionários eram depositados em uma urna lacrada, a qual foi aberta somente ao término da coleta pelo pesquisador responsável.

\section{Organização e análise de dados}

Os dados foram tabulados no programa estatístico SPSS versão 13.0, sendo utilizados: Teste-t para amostras independentes, para diagnosticar diferenças significativas entre homens e mulheres, e Teste de correlação de Pearson, para identificar possíveis correlaçôes entre as variáveis do QIC.

sexual, existe uma diferença significativa onde os homens gostam mais de variar os parceiros sexuais, receber sexo oral do parceiro/parceira e se masturbar, enquanto as mulheres alegam gostar mais de sexo com parceiro fixo.

No aspecto "percepção do prazer sexual", as mulheres, mais comumente que os homens, afirmam que o coração dispara e sentem contraçôes no momento do orgasmo. Em termos de "satisfação sexual", também são as mulheres que, com maior frequência, afirmam que ao perceberem-se amadas, sentem-se sexualmente satisfeitas e valorizam as carícias íntimas antes do sexo. Outros detalhes encontram-se na TABELA 3. 
TABELA 3 - Perfil sexual e corporal dos homens e mulheres participantes.

\begin{tabular}{|c|c|c|c|c|c|c|}
\hline \multirow{2}{*}{ Variáveis } & \multicolumn{2}{|c|}{ Homens } & \multicolumn{2}{|c|}{ Mulheres } & \multirow{2}{*}{$\begin{array}{c}\text { Teste } \\
\mathbf{T}\end{array}$} & \multirow{2}{*}{$\begin{array}{c}\text { Sig. } \\
\text { (2-tailed) }\end{array}$} \\
\hline & média & \pm & média & \pm & & \\
\hline Já viu a sua genitália & 2,9 & 0,5 & 2,5 & 0,8 & 2,817 & 0,000 \\
\hline Conhece a sua genitália & 2,8 & 0,5 & 2,5 & 0,8 & 3,274 & 0,000 \\
\hline Toca a sua genitália & 2,6 & 0,7 & 2,1 & 1,0 & 2,837 & 0,000 \\
\hline Se masturba & 2,0 & 0,9 & 1,5 & 1,2 & 2,630 & 0,000 \\
\hline Olha o corpo inteiro no espelho & 2,2 & 1,0 & 2,6 & 0,8 & $-2,518$ & 0,001 \\
\hline Utiliza apetrechos sexuais & 0,2 & 1,0 & 0,4 & 0,8 & $-1,501$ & 0,004 \\
\hline Faz sexo no primeiro encontro & 1,2 & 1,0 & 0,5 & 0,8 & 3,813 & 0,004 \\
\hline Gosta de sexo com parceiro fixo & 2,5 & 0,7 & 2,8 & 0,5 & $-3,016$ & 0,000 \\
\hline Gosta de variar parceiros sexuais & 1,5 & 1,1 & 0,3 & 0,6 & 6,600 & 0,000 \\
\hline Gosta de receber sexo oral do parceiro/a & 2,5 & 0,8 & 2,1 & 1,1 & 2,201 & 0,001 \\
\hline Gosta de masturbação & 1,9 & 0,8 & 1,6 & 1,1 & 1,513 & 0,001 \\
\hline No orgasmo o coração dispara & 2,2 & 0,9 & 2,7 & 0,6 & $-3,322$ & 0,002 \\
\hline No orgasmo sente contrações & 2,0 & 1,1 & 2,7 & 0,8 & $-3,511$ & 0,001 \\
\hline Ao sentir-se amado(a), sente-se sexualmente satisfeito(a) & 2,6 & 0,7 & 2,9 & 0,5 & $-2,439$ & 0,000 \\
\hline Valoriza carícias íntimas antes do sexo & 2,7 & 0,5 & 2,9 & 0,4 & $-1,676$ & 0,003 \\
\hline
\end{tabular}

Sig. (2-tailed) $\leq 0,005$. As respostas variaram de acordo com a seguinte escala: muito - médio - pouco - nunca.

\section{Perfil sexual de homens e mulheres}

De forma geral, homens e mulheres mais liberais em termos religiosos tendem a ser mais liberais em termos sexuais, porém, somente entre os homens encontrou-se correlação significativa entre ser mais liberal em termos sexuais e fazer sexo no primeiro encontro. Homens e mulheres mais conservadores em termos religiosos tendem a apreciar menos o sexo.
Independente do sexo biológico, aqueles que têm vida sexual com vários parceiros geralmente fazem sexo no primeiro encontro. As mulheres que têm prática masturbatória são as que mais relataram ter atividade sexual com vários parceiros sexuais e apresentam maior probabilidade de fazer sexo no primeiro encontro. Ainda, independente do sexo dos participantes, aqueles que têm atividade sexual apenas com parceiro fixo atingem mais rápido o orgasmo. Maiores informações são apresentadas na TABELA 4.

TABELA 4 - Correlações significativas com a sexualidade de homens e mulheres.

\begin{tabular}{lcc}
\hline \multicolumn{1}{c}{ Correlaçóes } & Mulheres & Homens \\
\hline 1. Ser liberal em termos sexuais x ser liberal em termos religiosos. & $0,482^{* *}$ & $0,457^{* *}$ \\
2. Ser liberal em termos sexuais x fazer sexo no primeiro encontro. & $\mathrm{ns}$ & $0,438^{* *}$ \\
3. Ser liberal em termos religiosos x gostar de sexo. & $-0,291^{*}$ & $-0,326^{*}$ \\
4. Se masturba x ter vida sexual com vários parceiros. & $0,318^{*}$ & $\mathrm{~ns}$ \\
5. Se masturba x faz sexo no primeiro encontro. & $0,453^{* *}$ & $\mathrm{~ns}$ \\
6. Ter vida sexual com apenas um parceiro x chegar mais rápido ao orgasmo. & $0,324^{*}$ & $0,315^{*}$ \\
7. Ter vida sexual com vários parceiros x fazer sexo no primeiro encontro. & $0,727^{* *}$ & $0,421^{* *}$ \\
8. Chegar rápido ao orgasmo x gostar de sexo. & $0,312^{*}$ & $\mathrm{~ns}$ \\
\hline
\end{tabular}

ns = não significativo. * Correlação significativa $p \leq 0,05$.

* Correlação significativa $p \leq 0,01$. As respostas variaram de acordo com a seguinte escala: muito - médio - pouco - nunca.

\section{Perfil da satisfação corporal e sexual}

Para checar possível relação entre níveis de satisfação corporal e sexual, analisaram-se algumas possíveis conexôes entre estas variáveis com as demais do QIC. Como forma de entender os diferentes níveis de satisfação com o próprio corpo buscou-se as correlações significativas com o seguinte item "estou satisfeito com o meu corpo", referente aos participantes em geral e controlando-se 
o sexo biológico. Os resultados obtidos podem ser visualizados na TABELA 5.

De forma geral, os participantes que afirmam gostar do seu próprio corpo tendem a achar que possuem um corpo bonito e proporcional, como também que causam boa impressão, independente do sexo. Como pode-se perceber, os participantes que afirmam estar satisfeitos com seu próprio corpo tendem a encontrar-se satisfeitos com sua vida sexual. No entanto, quando controladas as respostas dos participantes pelo sexo, esta correlação não é significativa entre as mulheres.

TABELA 5 - Correlações com o nível de satisfação corporal.

ns = não significativo. * Correlação significativa $p \leq 0,05$.

* Correlação significativa $p \leq 0,01$.

As respostas variaram de acordo com a seguinte escala: muito - médio - pouco - nunca.

\begin{tabular}{lccc}
\hline \multicolumn{1}{c}{ Variáveis } & Todos & Mulheres & Homens \\
\hline 1. Se está satisfeito com a vida sexual. & $0,247^{*}$ & $0,292^{*}$ & $\mathrm{~ns}$ \\
2. Ser liberal em termos religiosos. & $0,190^{*}$ & $\mathrm{~ns}$ & $\mathrm{~ns}$ \\
3. Praticar atividade física regularmente. & $0,219^{*}$ & $\mathrm{~ns}$ & $\mathrm{~ns}$ \\
4. Acha seu corpo sexualmente interessante. & $0,206^{*}$ & $0,330^{*}$ & $\mathrm{~ns}$ \\
5. Acha o seu corpo bonito. & $0,634^{* *}$ & $0,605^{* *}$ & $0,642^{* *}$ \\
6. Acha o seu corpo proporcional. & $0,575^{* *}$ & $0,301^{*}$ & $0,714^{* *}$ \\
7. Percebe que os outros o acham sexy. & $0,191^{*}$ & $\mathrm{~ns}$ & $\mathrm{~ns}$ \\
8. Acha que causa boa impressão. & $0,295^{* *}$ & $0,291^{*}$ & $0,326^{*}$
\end{tabular}

\section{Discussão}

\section{Diferenças em termos de corporeidade e sexualidade entre homens e mulheres}

As diferenças significativas entre os participantes referente aos quesitos "visualização da genitália", "conhecimento da própria genitália" e "toque da sua genitália" possivelmente estão relacionadas à maior exteriorização da genitália masculina que permite exploração acessível, bem como a valores culturais atrelados aos papéis de gênero. Nesse sentido, grande parte das culturas humanas tem profunda adoração ao falo masculino e, em contrapartida, apresenta atitude de recato e controle sobre o uso da genitália feminina (PARKER, 2002). Desta forma, práticas de exploração e uso da genitália masculina geralmente são socialmente vistas como positivas e sinônimo de fertilidade, força e poder. Assim, tocar, conhecer e manipular a genitália constituem-se importantes práticas para a construção do "macho" na maioria das sociedades, cabendo geralmente às mulheres preservar ou esconder a pureza genital, $\mathrm{o}$ que dificulta o acesso das mesmas a seu próprio corpo.

A exteriorização da corporeidade masculina em nossa sociedade pode advir também da herança greco-romana, já que para o antigo habitante de Atenas exibir-se confirmava a dignidade de cidadão (GIDDENS, 1993). O ato de se expor fazia de seu corpo algo a ser admirado como um templo, havendo certa cumplicidade entre o cidadão e a própria pólis (cidade).
Valor e culto ao físico eram fomentados por acreditarem na complementaridade entre corpo, mente e espírito.

Em relação ao "comportamento sexual", os homens mostraram-se mais desprendidos ao experimento sexual, pois nada têm a perder ao fazer uso de sua sexualidade, com exceção a algumas práticas sexuais com pessoas do mesmo sexo que em algumas culturas colocaria em risco a identidade de macho (Nolasco, 1990). Já as mulheres parecem estar mais subjugadas às normas do mercado sexual (CHADAROw, 1979), que se fundamentam na valorização do macho experimentado versus a mulher menos experiente. Em tal contexto, parece haver ênfase no próprio falo na estruturação da identidade de gênero masculina, o qual deve ser testado em termos de tamanho, forma, potência e funcionalidade.

O padrão sexual mais quantitativo dos homens, avaliado pelos evolucionistas como herança do processo evolutivo de nossa espécie, talvez se baseie na necessidade de formar laços de dominação com objetivo de adquirir status social e maior acesso às mulheres, resultando em insistente comportamento de autoafirmação social (BAKER, 1996). Já o comportamento sexual das mulheres parece estruturar-se em princípios mais afetivos, uma vez que estas não precisam provar socialmente o desempenho sexual ativo e não dão tanto valor ao tipo de "status" social que os homens procuram (Hite, 1987). A erotização do corpo das 
mulheres geralmente recebe mais estímulo a tornar-se objeto de desejo e apreço erótico ao público masculino.

No aspecto "percepção do prazer sexual", as mulheres têm percepção mais aguçada das manifestaçôes do orgasmo, descrevendo-o mais detalhadamente. Em termos de "satisfação sexual", faz-se necessário recorrer ao conceito de "Love Maps", ou seja, "mapas amorosos", para auxiliar na compreensão de como se dá a satisfação sexual em homens e mulheres.

Money (1986) define "mapas amorosos" como um esquema desenvolvimentista ou arquétipo na mente e no cérebro do amor idealizado, onde está projetada a atividade sexoerótica do indivíduo. Assim como a língua nativa, o "mapa amoroso" não está pronto no momento do nascimento, pois requer influências externas do meio para ser cunhado. O período crítico para o seu desenvolvimento não seria a puberdade, como muitos alegam, mas até por volta dos oito anos de idade. Portanto, as mulheres participantes dessa pesquisa sustentam os preceitos teóricos de MONEY (1986) quando afirmam que ao sentirem-se amadas, sentem-se satisfeitas sexualmente.
Por mapa normofílico Money (1986) entende o mapa amoroso típico da maioria da população, a qual consegue articular amor e sexo em um mesmo objeto de prazer, ou seja, em uma mesma pessoa. O mapa amoroso normofílico também apresenta diferentes níveis dessa articulação entre amor e sexo. Algumas pessoas não conseguem separar esses dois aspectos, tendo atividade sexual apenas quando amam, enquanto outras conseguem distinguir e vivenciar somente o sexo em algumas situações. Por mapa parafílico Money (1986) compreende o mapa amoroso de uma minoria da população que apresenta dificuldade de conectar, mesmo eventualmente, amor e sexo. Assim, o parafílico desenvolve sexualidade considerada por muitos como exótica ou "desviante" ao incluir outros aspectos não comuns em sua vida sexual. Enfim, os parafílicos desenvolvem desejo sexual por situaçóes ou objetos atípicos, como o comportamento sexual explícito sadomasoquista, por exemplo, entre outros (Moner, 1986). A FIGURA 1 ilustra essa graduação dos mapas amorosos humanos.

\section{ZONAS DE INTERAÇÃO AMOR-TESÃO}
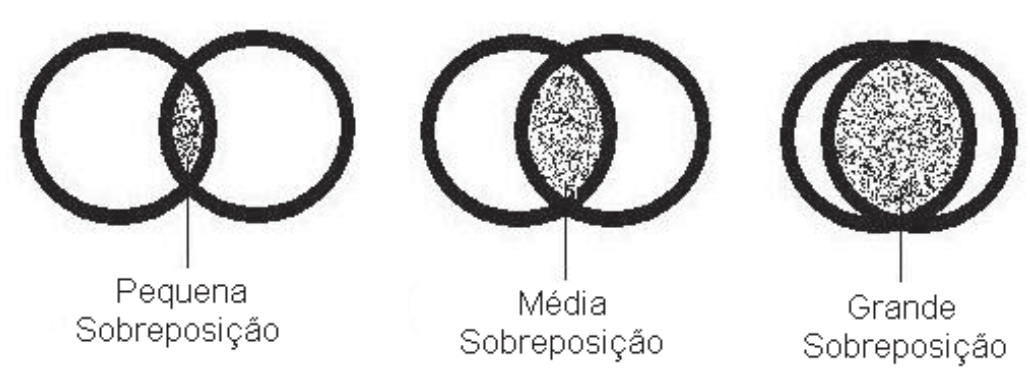

Fonte: MORIN (1995).

FIGURA 1 - Concepção de Mapa Amoroso Humano Normofílico proposto por J ohn Money.

A diversidade de mapas amorosos trata-se de algo típico da nossa espécie, sendo que as mulheres em média tendem a ter uma maior sobreposição entre o erótico e o amor em comparação aos homens, os quais conseguem com maior facilidade distingui-los e vivenciá-los com maior ou menor sobreposição. De acordo com ABDO (2004), no Brasil 77\% das mulheres relacionam bom desempenho e satisfação sexual com afeto e sentimento no sexo, sendo o mesmo encontrado em $62 \%$ dos homens. Mais de $60 \%$ dos homens e aproximadamente $80 \%$ das mulheres concordam que tem de haver afeto para um bom desempenho e satisfação sexual; $40 \%$ das mulheres relacionam satisfação sexual com compromisso na relação enquanto o mesmo ocorre com apenas 29\% dos homens. Cabe ressaltar que diferenças entre homens e mulheres nesses quesitos podem ser fortemente influenciadas por questôes socioeconômicas distintas, nem sempre controladas.

\section{Perfil sexual de homens e mulheres}

De acordo com o estudo atual, homens e mulheres mais liberais em termos religiosos tendem a ser mais liberais em termos sexuais, corroborando com a literatura internacional (PluHar, Frongillo, Stycos \& Dempser-McClain, 1998) e brasileira (Santa INEZ, 1983), porém homens, com mais frequência que as mulheres, fazem sexo no primeiro encontro, $\mathrm{o}$ que seria explicado por GIDDENS (1993) ao observar que a sexualidade masculina tende a expressar mais inquietação e objetividade do que a feminina, uma vez que os homens separam a sua atividade sexual das outras atividades da vida.

Os homens tendem a se masturbar mais do que as mulheres, o que já foi percebido por KINSEY, POMEROY e Martin (1948) e Kinsey, Pomeroy, Martin e GeBHARD (1953) nos EUA, MASTER e JOHnSOns (1966) 
e também Laumann, Gagnon, Michael e Michaels (1994). No Brasil, o mesmo achado foi encontrado por SANTA INEZ (1983). Outro dado do presente estudo refere-se ao sexo oral, o qual os homens alegam gostar de recebê-lo. Os achados de SANTA InEz (1983) mostram que existe rejeição maior desta prática entre as mulheres e pessoas mais velhas no Brasil, o que justificaria os conflitos de relacionamento sexual entre homens e mulheres, como também gerações.

Nesse estudo, os homens tendem a ter mais parceiros sexuais do que as mulheres, fato já evidenciado na literatura internacional e no Brasil por ABDO (2004), onde em média as mulheres têm 1,4 parceiros sexuais nos últimos 12 meses enquanto os homens têm 2,9 durante o mesmo período, ou seja, os homens tiveram o dobro de parcerias sexuais.

Homens e mulheres que assumem ter mais parceiros sexuais são aqueles que se sentem à vontade para fazer sexo no primeiro encontro. As mulheres que têm prática masturbatória, isto é, que conhecem melhor o seu corpo, são aquelas que se permitem experimentar vários parceiros sexuais e têm maior propensão à não valorizar os tradicionais estigmas ligados à noção de promiscuidade.

Um outro aspecto interessante verificado consiste na correlação positiva encontrada entre o conhecimento íntimo do corpo do parceiro sexual, entre aqueles que têm parceiros fixos, com a rapidez para se atingir o orgasmo, o que implicaria em domínio sobre a gratificação sexual.

\section{Considerações finais}

O fato dos homens participantes desta pesquisa demonstrar maior intimidade com seu corpo nos remete ao processo evolutivo tanto da espécie quanto da cultura humana. Quando analisamos o ser humano a partir do seu "anthropos", isto é, da relação entre natureza e cultura, admitimos as forças da natureza que nos permitiram passar genes e sobreviver às pressōes da natureza, mas também reconhecer a evolução da organização social humana que criou a diversidade cultural entre os homo sapiens. Assim, não são poucos os trabalhos de antropólogos e pesquisadores da corporeidade humana que ilustram o impacto dessa diversidade cultural nos usos e significados do corpo em cada cultura.

Em relação à satisfação sexual e corporal, entramos em um paradoxo em termos simbólicos, pois apesar das mulheres sentirem-se mais cobradas pela

\section{Perfil da satisfação corporal e sexual}

Os participantes que afirmam estar satisfeitos com o seu próprio corpo também estão satisfeitos com a vida sexual e se percebem como indivíduos sensuais, o que implica em relação direta entre aceitação corporal e auto-estima - princípios importantes para o indivíduo operar no "mercado sexual". No entanto, a ênfase social no corpo perfeito feminino pode estar levando a maioria das mulheres a preocupação exagerada com a estética, o que talvez esteja afetando diretamente sua percepção de satisfação corporal e indiretamente sua percepção de satisfação sexual. Muraro (1983) já havia registrado essa percepção funcional do corpo na visão dos homens em relação à percepção estética na visão das mulheres. Além disso, os homens veem seu corpo como algo dissociado do eu, isto é, como instrumento: "meu corpo é apenas parte do meu eu".

SALIMENE (1995) também pesquisou acerca das diferenças entre percepção corporal e sexual de homens e mulheres. A autora sugere que as mulheres veem seu corpo como objeto de erotização, talvez forjado pela cultura machista, enquanto os homens relacionam sua percepção sexual ao funcional e comportamental.

Esse estudo ainda verificou que os participantes mais satisfeitos com o seu corpo afirmam ser praticantes regulares de atividade física e geralmente são do sexo masculino, o que pode expressar ênfase funcional e relacionada à saúde nas suas percepções de satisfação.

sociedade devido ao "culto ao corpo perfeito" e, talvez por isso sintam-se menos satisfeitas com seu corpo, praticam menos atividade física que os homens, os quais, por sua vez, encontram-se mais satisfeitos com o próprio corpo e com a vida sexual. Esses resultados demonstram que os homens parecem mais preocupados com o desempenho sexual do que com a aparência física enquanto as mulheres acreditam que apenas podem se realizar sexualmente e sentirem-se desejadas ao obter o corpo perfeito. Outros estudos ainda demonstram maior dependência social ou de contexto das mulheres em relação aos homens.

A partir dos achados apresentados poderíamos reunir muitos outros argumentos de cunho evolucionista ou culturalista para explicar o comportamento corporal e sexual de homens e mulheres como, por exemplo, a igualdade social, econômica 
e sexual entre homens e mulheres na atualidade e a falta de interesse por parte delas em pornografia. Entretanto, cabe ressaltar que o presente estudo limitou-se a poucos participantes com características pouco típicas da nossa sociedade e os resultados aqui apresentados e discutidos refletem apenas esse ethos social específico.

O mais importante e grande propósito desse artigo foi o de trazer para a Educação Física a discussão que já ocorre em outras áreas da ciência e que poderia colaborar em muito com os atuais problemas teóricos encontrados na área do desenvolvimento motor humano infantil (SABBAG, CARDOSO \& SilveIRA, 2008) e as dificuldades pedagógicas relacionadas a autoestima corporal, "bullying", entre outros (Levandoski, 2009). CARdoso (2008a, b) também estuda o impacto da sexualidade sobre a identidade de gênero e a motricidade humana.

\section{Abstract \\ Corporal knowledge implications in sexual behavior}

This research aimed to identify and compare the corporeity and sexuality aspects of male $(n=54)$ and female $(n=54)$ participants with distinct sexual and gender orientations at the I Floripa Diversity Games, in Florianópolis, July/ 2006, using the Questionnaire of Body Identity - OIC anonymously. The main objectives of this study were to identify the differences in terms of corporeity and sexuality among men and women; women's and men's sexual profile, as well as the profile of the corporal and sexual satisfaction for each sex. Participants who affirm to like their body tended to consider themselves beautiful and proportional and believe that they cause good impression. Participants with corporal satisfaction tended to be also sexually satisfied, however, when we controlled the sex factor, only males keep this correlation. Men demonstrate greater corporal intimacy while women value intimate caresses as foreplays. Participants with regular partner reach orgasm easier although women are more sensitive to body reactions.

UnITERMS: Sexuality; Bodily feelings; Man; Woman; Diversity.

\section{Referências}

ABDO, C. Descobrimento sexual do Brasil. São Paulo: Summus, 2004.

BAKER, R. Sperm wars: the science of sex. New York: Harper Collins, 1996.

BRANNON, L. Gender: psychological perspectives. Boston: Allyn and Bacon, 1999.

CARDOSO, F. L. Noções de corporeidade: de quem e para quem? Motrivivência, Florianópolis, v.5, p.170-7, 1994a. . O gênero e o movimento humano. Revista Brasileira de Ciências do Esporte, Campinas, v.15, p.265-8, $1994 \mathrm{~b}$. . Diferença sexual: o diacronismo das teorias sobre o gênero. In: ROMERO, E. (Org.). Mulheres em movimento. Vitória: EDUFES, 1997. p.65-80.

. O conceito de orientação sexual na encruzilhada entre sexo, gênero e motricidade. Interamerican Journal of Psychology, Porto Alegre, v.42, p.69-79, 2008a.

. Recalled sex-typed behavior in childhood and sports preferences in adulthood of heterosexual, bisexual, and homosexual men from Brazil, Turkey, and Thailand. Archives of Sexual Behavior, New York, v.37, p.565-77, 2008 b.

CHADAROW, N. Estrutura familiar e personalidade feminina. In: ROSALDO, M.; LAMPHERE, L. (Orgs.). A mulher, a cultura, a sociedade. Rio de Janeiro: Paz e Terra, 1979.

DAVIS, F. A comunicação não-verbal. São Paulo: Summus, 1979.

DOUGLAS, M. The two bodies: natural symbols. New York: Pantheon Books, 1970.

DUMONT, L. The individual as an impediment to sociological comparison and Indian history. In: DUMONT, L. Religion, politics and history in India. Paris: Mouton, 1970.

FOUCAULT, M. A história da sexualidade I. Rio de Janeiro: Edições Graal, 1988.

GIDDENS, A. A transformação da intimidade: sexualidade, amor e erotismo nas sociedades modernas. São Paulo: UNESP, 1993. HITE, S. Women and love: a cultural revolution in progress. New York: Alfred Knopf, 1987. 
KINSEY, A.; POMEROY, W.; MARTIN, C. Sexual behavior in the human male. Philadelphia: Saunders, 1948. KINSEY, A.; POMEROY, W.; MARTIN, C.; GEBHARD, P. Sexual behavior in the human female. Philadelphia: Saunders, 1953.

LAUMANN, E.O.; GAGNON, J.H.; MICHAEL, R.T.; MICHAELS, S. The social organization of sexuality: sexual practices in the United States. Chicago: University of Chicago, 1994.

LEVANDOSKI, G. Análise de fatores associados ao comportamento bullying no ambiente escolar: características cineantropométricas e psicossociais. 2009. Dissertação (Mestrado em Ciência do Movimento Humano) - Universidade do Estado de Santa Catarina.

MASTER W.H.; JOHNSONS, V.E. Human sexual response. Boston: Little Brown, 1966.

MAUSS, M. As técnicas corporais. In: MAUSS, M. Sociologia e antropologia. São Paulo: EPU/EDUSP, 1974.

MONEY, J. Love maps: clinical concepts of sexual/erotic health and pathology, paraphilia, and gender transposition in childhood, adolescence, and maturity. New York: Irvington, 1986.

MORIN, J. The erotic mind. New York: Haper Collins, 1995.

MURARO, R.M. Sexualidade da mulher brasileira: corpo e classe social no Brasil. Petrópolis: Vozes, 1983.

NOLASCO, S. A expressão das emoções e o desejo masculino: algumas considerações sobre a identidade masculina In: BRANDĀO, M.(Org.). Teologia da ótica da mulher. Rio de Janeiro: PUC/Nem, 1990.

PARKER, E. The phallus palace. Los Angeles: Dean Kotula, 2002.

PLUHAR, E.; FRONGILLO, E.A.; STYCOS, J.M.; DEMPSER-McCLAIN, D. Understanding the relationship between religion and the sexual attitudes and behaviors of college students. Journal of Sex Education and Therapy, New York, v.23, p.288-96, 1998.

RODRIGUES, J.C. Tabu do corpo. Rio de Janeiro: Dois Pontos, 1996.

SABBAG, S.; CARDOSO, F.L.; SILVEIRA, R. Motricidade fina e global de meninos e meninas: uma comparação. Revista Científica JOPEF, Curitiba, v.1, p.291-96, 2008.

SALIMENE, A.C.M. Sexo: caminho para a reabilitação. São Paulo: Cortez, 1995.

SANTA INEZ, A.L. Pesquisa acerca dos hábitos e atitudes sexuais dos brasileiros. São Paulo: Cultrix, 1983.

SCOTT, J. Gênero uma categoria útil de análise histórica. Educação e Realidade, Porto Alegre, v.16, p.5-22, 1990.

VIVEIROS DE CASTRO, E. A fabricação do corpo na sociedade Xinguana. In: OLIVEIRA FILHO, J.P. (Org.). Sociedade indígena e indigenismo no Brasil. Rio de Janeiro: Marco Zero, 1987. p.31-41.

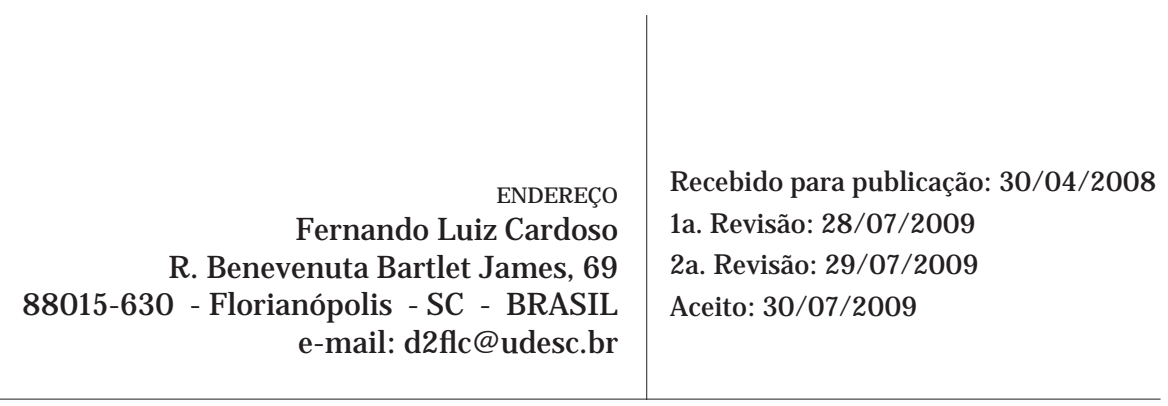

